\title{
A new assessment of perforation skin factor for vertical perforated wells in near-wellbore region
}

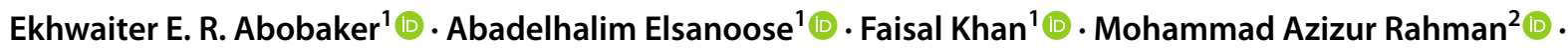 \\ Amer Aborig $^{1} \cdot$ Khalid Noah $^{3}$. Stephen Butt ${ }^{1}$
}

Received: 17 July 2021 / Accepted: 11 October 2021 / Published online: 25 October 2021

(C) The Author(s) 2021

\begin{abstract}
The perforating technique is one of the well completion methods and a final stage that helps connect reservoir formation to wellbore during hydrocarbon production. The present work aimed to determine the effect of the perforated casing completion on the pressure gradient and perforation skin factor in the vertical near-wellbore region. This work presented a novel experimental approach for studying the effect of perforation parameters on hydrocarbon production by creating a prototype representing the near-wellbore region. The study conducted extensive laboratory testing to create two prototype artificial samples for a cylindrical near-wellbore region, open hole, and perforated casing sample. An experimental test was carried out using a geotechnical radial flow setup to measure the differential pressure in the two samples; the single-phase (water) was radially injected into the core sample within the same flow boundary conditions. Numerical simulation and statistical analysis were used to expand the investigation of the effect of the dimensions and distribution of perforations on the perforation skin factor and the pressure gradient in the cylindrical near-wellbore region. The results showed a clear view of the effect of the perforations' parameters on the pressure gradient in the vertical near-wellbore region. In addition, two novel correlations were produced from statistical analysis that simplified the estimation of the perforation skin factor in the perforated casing completion. This study will help to clarify and understand the effect of perforation parameters on well productivity.
\end{abstract}

Keywords Radial flow cell · Artificial sandstone sample $\cdot$ Near-wellbore region $\cdot$ Perforation skin factor

$\begin{array}{ll}\text { List of Symbols } \\ \vec{B}_{f} & \text { Body force } \\ C_{2} & \text { Inertial resistance factor } \\ D & \text { Diameter of sample } \\ d_{p} & \text { Perforation diameter } \\ H & \text { Sample height } \\ h & \text { Formation thickness } \\ h_{p} & \text { Perforation space } \\ k_{d} & \text { Permeability of damaged zone } \\ k_{f} & \text { Formation permeability } \\ k_{h} & \text { Horizontal permeability } \\ K_{r} & \text { Permeability ratio }\end{array}$

Ekhwaiter E. R. Abobaker

eera48@mun.ca

1 Faculty of Engineering and Applied Science, Memorial University of Newfoundland, St. John's, NL A1C 5S7, Canada

2 Petroleum Engineering, Texas A\&M University at Qatar, 23874 Doha, Qatar

3 Faculty of Engineering, University of Tobruk, Tobruk, Libya $k_{v}$

$J_{d}$

$J_{o}$

$L_{d}$

$l_{p}$

$\stackrel{l^{\prime}}{Q}$

$P_{r}$

$p_{e}$

$p_{w}$

$r_{e}$

$r_{p}$

$R_{r}$

$r_{s}$

$r_{w}$

$r_{w}^{\prime}$

$S_{h}$

$S_{p}$

$S_{v}$

$S_{w c}$

$\vec{v}$

$\gamma$
Vertical permeability

Productivity index for a well with skin factors

Productivity index for an ideal open hole

Damaged zone length

Perforation length

Modified perforation length

Flow rate

Penetration ratio

Pressure at the external boundary of reservoir

Pressure inside wellbore

Reservoir radius

Radius of perforation tunnel

Radius ratio

Skin zone radius

Wellbore radius

Modified wellbore radius

Horizontal perforation skin factor

Skin due to ideal perforations

Vertical perforation skin factor

Wellbore skin factor

Velocity

Porosity 


$\begin{array}{ll}\gamma_{f} & \text { Porosity of formation zone } \\ \gamma_{s} & \text { Porosity of skin zone } \\ \theta & \text { Perforation angle } \\ \theta_{d} & \text { Ratio of perforation angle to } 180^{\circ} \\ \mu & \text { Fluid viscosity } \\ \frac{\rho}{\bar{\tau}} & \text { Fluid density } \\ \Delta p & \text { Stress tensor related to viscous flow }\end{array}$

\section{Abbreviation}

$\begin{array}{ll}\text { ANOVA } & \text { Analysis of variance } \\ \text { BBD } & \text { Box-Behnken design } \\ \text { CFD } & \text { Computational fluid dynamics } \\ \text { DQ } & \text { Data acquisition } \\ \text { DoE } & \text { Design of experiments } \\ \text { IPR } & \text { Inflow performance relationship } \\ \text { PD } & \text { Perforation by drilling } \\ \text { PR } & \text { Productivity index } \\ \text { PSD } & \text { Pore size distribution } \\ \text { RSM } & \text { Response surface methodology }\end{array}$

\section{Introduction}

The last stage in well construction is known as well completion, which is also the first stage to move the reservoir toward production status. To finish a well, an appraisal of the reservoir's quality must be made. The appraisal considers aspects such as the properties of the reservoir rock (e.g., permeability and porosity) as well as saturation and type of interstitial water and hydrocarbon fluids. Therefore, the production engineers must have a variety of tools available for designing an appropriate completion plan in accordance with reservoir fluid characteristics, the production rate for casting, and rock formation type. Because the process of well completion is costly, the majority of these wells must be able to quickly produce large amounts of hydrocarbon to ensure an attractive and rapid return on investment. However, the process of drilling itself impairs the reservoir rock permeability, decreasing the reservoir's natural productivity. This phenomenon is called "formation damage" and is mainly caused by the completion process, drilling, stimulation, and other activities (Yuan \& Wood, 2018). One of the main contributing factors to well components is formation damage, which may significantly affect productivity. In general, well productivity has been documented as being affected by a number of interacting elements, including the diameter of the casing entrance hole, the depth and density of perforations, and boundary flow conditions. Perforation is used to connect reservoir formations to wellbores during hydrocarbon production stages. Although the primary purpose of using perforation is to boost production, its application can also cause issues with virgin reservoirs (Renpu,
2011). Perforations can be created using a variety of methods (Behrmann et al. 2002), and their success is related to a number of characteristics, including radius, phasing angle, density, and length of perforation (Economides, 2013). Here, a flow path is generated between the wellbore and pay zone that affects the efficiency of the well's operation (Economides \& Nolte, 2000). For the mentioned factors (radius, phasing angle of perforations, etc.), the total and combined effect can typically be attributed to one parameter only, which is the total skin factor. In general terms, the total skin factor measures the productivity of a well. Skin factor may also provide a measure for pressure drop in perforated completion in comparison with the ideal pressure drop that is predicted using the radial flow theory for similar flow rates. Perforation skin models for vertical wells have been presented in various studies for more than 50 years (Harris 1966; Klotz et al. 1974; Locke 1981; Karakas and Tariq 1991; Yildiz 2006). Klotz et al. (1974) employed a 2-D finite element model to examine how perforations and formation damage at the crushed zone affect well productivity, while Locke (1981) looked at a novel way (nomograph) to estimate skin for perforated completions. Nomographs can take skin factors into account by considering rock compaction and formation damage at perforation tunnels. Using a finite element simulator, Karakas and Tariq (1991) formulated several empirical equations for predicting the total skin factor at fully perforated vertical wells. Yildiz (2006) proposed a novel way to assess the total skin factor that accounted for a large number of other factors, including compaction zone skin, perforation skin, drill-damaged skin, and the impact of partial formation perforation. In particular, the model of Karakas and Tariq (1991) has been commonly used in the industry for the past three decades.

There have been significant improvements in computational fluid dynamics (CFD) and computers during the last two decades. The improvements permit the running of significantly larger models and finer meshes for significantly lower cost and time expenditures. As well, the improvements include revisions to field development strategies in relation to horizontal and deviated wells and upgrades to perforating technology in relation to increased penetration depths. Several recent studies have used CFD for simulating flows in porous media, especially near perforations and wellbore regions, which is becoming more widespread, due largely to improvements in computer technology. CFD technology can easily and quickly model complex interactions' flow occurring in a near-wellbore region (Wood et al. 2020), including formation damage and completion geometry. Using CFD, the well's completion is expedited by formatting the well as a grid and dealing with each small section individually. Reservoir heterogeneity and formation damage can also be captured for a well, which allows for a significantly more detailed examination of the well and near-wellbore area, 
resulting in improved estimations for inflow performance. For example, Byrne et al. (2009) used CFD to model well inflow at a perforated vertical well. Also, Byrne et al. (2010 and 2011) demonstrated how CFD could resolve asymmetric distribution formation damage near the well and capture the cross flow in the layered reservoir with a heterogeneous. A few years later, the same researchers developed a model for a perforated horizontal well (Byrne et al. 2014). Additionally, Molina and Tyagi (2015) applied CFD on a near-well model to examine how a perforated gas well performs, looking in particular at various types of completion techniques and how these strategies might have erosive effects at the wellbore. This study is an extension of the works (Zheng, et al. 2016; Ahammad, et al. 2018, 2019; Abobaker et al. 2021a, 2021b) for investigating single fluid flow occurring in perforated porous substances numerically and experimentally. The researchers' model was able to predict the pressure gradients of petrophysical characteristics within perforation tunnels and the near-wellbore regions. The present research attempts to determine how the dimensions and distribution of perforations affect skin factors by conducting four main investigative procedures of the sample preparation, experimental method, numerical simulation, and statistical analysis. Also considered in this work is how skin factor and other completion characteristics affect the productivity ratio. The experimental and numerical studies were carried out to present a better understanding of the fluid flow dynamics in both perforations and casing and to determine how important design is in flow distribution near a wellbore. This approach allows for pressure drop in various completion configurations to be studied and analyzed and allows flow convergence-affected corresponding skin to be measured. In addition, the study also develops simple correlations for predicting the perforation skin factor for perforated vertical wells and compares the validity of the correlations with the available model of Karakas and Tariq (1991) for the specified reservoir and perforating parameters.

\section{Methodology}

In porous media, fluid flow at low velocities typically obeys Darcy's law. However, as the flow velocity increases, a nonDarcy flow regime begins to develop, caused by the increasingly nonlinear relationship between the local pressure gradient and in situ fluid velocity. Open-hole well completion is both the simplest and most popular completion strategy used in the oil and gas hydrocarbon industry today. Constructing a productivity model of vertical open holes is also relatively straightforward. Through integrating the relevant data with Darcy's equation, a well-productivity model can be built that describes open-hole well production in steady-state flows (Darcy, 1956):

$$
Q=\frac{2 \pi k_{f} h\left(p_{e}-p_{w}\right)}{\mu \ln \left(\frac{r_{e}}{r_{w}}\right)}
$$

The flow rate $(Q)$ for a vertical well in a cylindrical near-wellbore region with perforations, anisotropy permeability and Darcy flow perpendicular to the wellbore is expressed as (Economides, 2013):

$Q=\frac{2 \pi k_{f} h\left(p_{e}-p_{w}\right)}{\mu\left[\ln \left(\frac{r_{e}}{r_{w}}\right)+S_{p}\right]}$

Hydrocarbon wells can be affected by a number of skin factors. These effects include perforation skin factor $\left(S_{p}\right)$; any difference between an actual well's performances compared to that of an ideal vertical open hole is expressed as the perforation skin factor. The perforation skin factor can be obtained after the pressure drop is calculated from the equation:

$S_{p}=\frac{2 \pi k_{f} h\left(p_{e}-p_{w}\right)}{Q \mu}-\ln \left(\frac{r_{e}}{r_{w}}\right)$

To better understand how skin factors can affect the productivity of a well, the productivity index for an ideal open hole $\left(J_{o}\right)$ is compared to that for a well with skin factors $\left(J_{d}\right)$ (Economides, 2013):

$\Delta p=\frac{\mathrm{Q} \mu}{2 \pi k_{f} h}\left[\ln \left(r_{e} / r_{w}\right)+S_{p}\right]$

$J_{d}=\frac{\mathrm{Q}}{\Delta p}=\frac{2 \pi k_{f} h}{\mu\left[\ln \left(r_{e} / r_{w}\right)+S_{p}\right]}$

To quantify the comparison, the productivity ratio (PR) is applied, as expressed (Economides, 2013):

$P R=\frac{J_{d}}{J_{o}}=\frac{\ln \left(r_{e} / r_{w}\right)}{\ln \left(r_{e} / r_{w}\right)+S_{p}}$

In the literature, some studies calculate the total skin factor by adding together all of the above-mentioned skin factors. Karakas and Tariq's model is commonly applied when estimating how a well's productivity is influenced by perforation. There are two scenarios: the perforation tunnel exceeds the formation damaged zone, or the perforations remain within the formation damaged zone. Karakas and Tariq (1991) developed a procedure to calculate the perforation skin factor. The perforation skin factor is a 
combination including the horizontal flow effect $\left(S_{h}\right)$, the vertical converging effect $\left(S_{v}\right)$, and the wellbore $\operatorname{effect}\left(S_{w b}\right)$.

Hence,

$S_{p}=S_{h}+S_{v}+S_{w b}$

The horizontal perforation skin factor, $S_{h}$, is given by:

$S_{h}=\ln \left(\frac{r_{w}}{r_{w}(\theta)}\right)$

where $r_{w}^{\prime}(\theta)$ is the efficient wellbore radius and is a function of the perforation angle $\theta$.

$r_{w}^{\prime}(\theta)=\left\{\begin{array}{lr}l_{p} / 4 & \text { if } \theta=0 \\ \alpha \theta\left(r_{w}+l_{p}\right) & \text { otherwise }\end{array}\right\}$

where $l_{p}$ is the perforation's length, and $\alpha \theta$ is phase dependent on variables obtain from Table 1.

The vertical perforation skin effect is then given by Karakas and Tariq (1991):

$S_{v}=10^{a} h_{d}^{b-1} r_{p d}^{b}$

where $h_{d}, r_{p d}, a$ and $b$ are given by:

$h_{d}=\frac{h_{p}}{l_{p}} \sqrt{\frac{k_{h}}{k_{v}}}$

$r_{p d}=\frac{r_{p e r}}{2 h_{p}}\left(1+\sqrt{\frac{k_{v}}{k_{h}}}\right)$

Table 1 Dependency of $r_{w}^{\prime}(\theta)$ on phasing

\begin{tabular}{ll}
\hline Perforating phasing & Phase $(\alpha \theta)$ \\
\hline $0^{\circ}\left(360^{\circ}\right)$ & 0.25 \\
$180^{\circ}$ & 0.5 \\
$120^{\circ}$ & 0.648 \\
$90^{\circ}$ & 0.726 \\
$60^{\circ}$ & 0.813 \\
$45^{\circ}$ & 0.860 \\
\hline
\end{tabular}

$a=a_{1} \log \left(r_{p d}\right)+a_{2}$

$b=b_{1} r_{p d}+b_{2}$

Finally, the wellbore skin effect, $S_{w b}$, can be obtained by Karakas and Tariq (1991):

$S_{w b}=c_{1} e^{c_{2} r_{w d}}$

where $r_{w d}$ is given by

$r_{w d}=\frac{r_{w}}{l_{p}+r_{w}}$

The constants $a_{1}, a_{2}, b_{1}, b_{2}, c_{1}$ and $c_{2}$ are given in Table 2 as functions of the perforation angle, $\theta$.

Karakas and Tariq (1991) suggested using a modified perforation length $l_{w}^{\prime}$ and the modified wellbore radius $r_{w}^{\prime}$ when the perforation tunnel exceeds the formation damaged zone.

$r_{w}^{\prime}=r_{w}+\left(1-\frac{k_{d}}{k_{f}}\right) L_{d}$

$l_{w}^{\prime}=l_{p}-\left(1-\frac{k_{d}}{k_{f}}\right) L_{d}$

Using Karakas and Tariq's semi-analytical model as a foundation and reference point, the present study aims to compare and extend the investigations of near-wellbore region flow, thereby expanding industry knowledge about well performance. This study involved four main investigative procedures of sample preparation, experimental, numerical, and statistical analysis for a more accurate estimation of the perforation skin factor for perforated wells. The experimental approach has been used to validate the numerical model for single-phase flow through the two perforation samples. Statistical analysis has been coupled with numerical simulation to expand the investigation of fluid flow in the near-wellbore region that cannot be obtained experimentally, due to the limitations of the experimental setup, especially the small sample size.
Table 2 Vertical and wellbore skin correlation coefficients

\begin{tabular}{lllllll}
\hline $\begin{array}{l}\text { Perforating phas- } \\
\text { ing }(\theta)\end{array}$ & $a_{1}$ & $a_{2}$ & $b_{1}$ & $b_{2}$ & $c_{1}$ & $c_{2}$ \\
\hline $0^{\circ}\left(360^{\circ}\right)$ & -2.091 & 0.0453 & 5.1313 & 1.8672 & $1.6 \times 10^{-1}$ & 2.675 \\
$180^{\circ}$ & -2.025 & 0.0943 & 3.0373 & 1.8115 & $2.6 \times 10^{-2}$ & 4.532 \\
$120^{\circ}$ & -2.018 & 0.0634 & 1.6136 & 1.7770 & $6.6 \times 10^{-3}$ & 5.320 \\
$90^{\circ}$ & -1.905 & 0.1038 & 1.5674 & 1.6935 & $1.9 \times 10^{-3}$ & 6.155 \\
$60^{\circ}$ & -1.898 & 0.1023 & 1.3654 & 1.6490 & $3.0 \times 10^{-4}$ & 7.509 \\
$45^{\circ}$ & -1.788 & 0.2398 & 1.1915 & 1.6392 & $4.6 \times 10^{-5}$ & 8.791 \\
\hline
\end{tabular}




\section{Samples preparation}

Prototype artificial samples have been created that mimic a near-wellbore region, utilizing two zones with different levels of permeability. The model features cylindrical geometry as a means to enable radial flow toward the borehole, while the boundary condition has been set to a constant mass flow rate to help monitor any pressure changes occurring at/near the wellbore. As sourcing natural samples can be both expensive and challenging, and because these samples, if found, are often anisotropic (i.e., display various characteristics depending on how they are analyzed), laboratories tend to rely on models. Therefore, many researchers have presented different ways to create artificial samples. Holt et al. (2000) looked at synthetic samples for simulating in situ rock conditions. Their results showed how synthetic specimens are interchangeable with the real core in laboratory tests. In similar work, Butt (1999) investigated samples taken from a mine area in Nova Scotia, Canada, and also Ahammad et al. (2018) tested real and artificial samples in a laboratory. Laboratory samples are generally prepared according to study specifications and other factors. For our purposes, we investigated the samples using an experimental setup that has a broad range of applications related to near-wellbore flow phenomena (e.g., formation damage), which occurs at the well completion stage. In the laboratory experiments, two highly permeable artificial sandstone samples were prepared. The two cylindrical samples were made from sand particles measuring 0.18 to $1.18 \mathrm{~mm}$. Each artificial sample was created from two different sandstone grain sizes. The fine grain size was used to create a skin zone region (S1) around the wellbore, and the coarse grain size was used to create a formation reservoir zone $(\mathrm{S} 2)$. The sandstone particles and waterproof marine epoxy were mixed in different quantities (depending on the size of the sand) using an electric mixer for $10 \mathrm{~min}$. The mixture was then placed in a plastic container throughout four different stages, using an electric vibrator to ensure the distribution of grain with epoxy glue. Each sample was constructed in two stages; the skin zone was created and then perforated in the first stage, and the formation zone was created by putting the mixture of coarse grains (S2) around the skin zone. The first sample was not perforated (open hole), the second one cased and perforated ( 8 perforations). The dimensions of the two samples included perforation parameters, as shown in Table 3.

The perforation by drilling (PD) technique was used to create the perforations in this study. This technique has been used by Rahman et al. (2006, 2007a, 2007b and
Table 3 The dimensions of synthetic samples

\begin{tabular}{ll}
\hline Dimensions and properties the sample & Values (units) \\
\hline Sample height $(\mathrm{H})$ & $30.48 \mathrm{~cm}$ \\
Diameter of sample (D) & $15.24 \mathrm{~cm}$ \\
Wellbore radius $\left(r_{w}\right)$ & $1.27 \mathrm{~cm}$ \\
Skin zone radius $\left(r_{s}\right)$ & $5.08 \mathrm{~cm}$ \\
Perforation radius $\left(r_{p}\right)$ & $1.5 \mathrm{~mm}$ \\
Perforation length $\left(l_{P}\right)$ & $3.81 \mathrm{~cm}$ \\
Perforation space $h_{p}$ & $3.81 \mathrm{~cm}$ \\
Perforation angle $(\theta)$ & $90^{\circ}$ \\
\hline
\end{tabular}

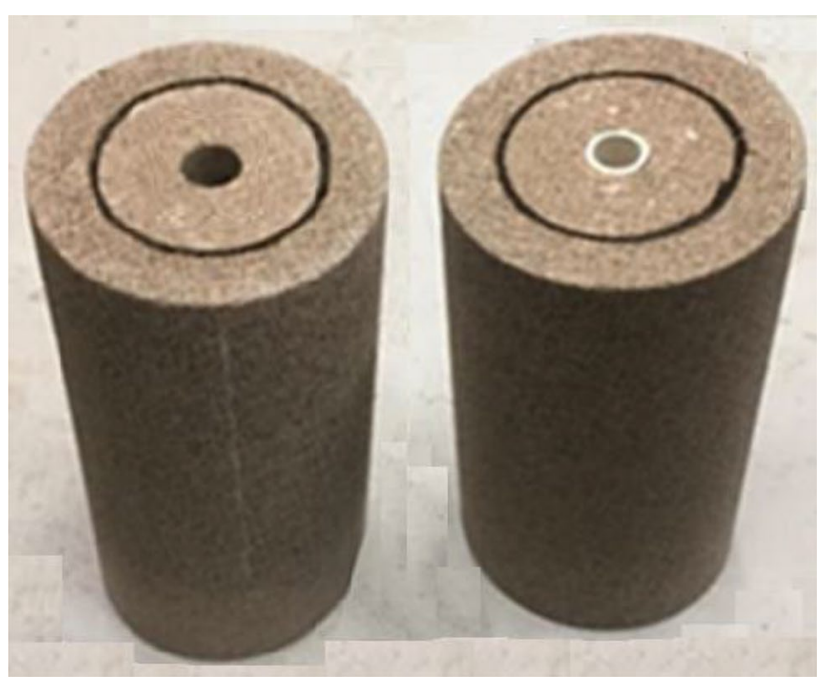

Fig. 1 The shape of two artificial sandstone samples

2008), as it does not create any transient shockwaves at the perforation tunnel during drilling. They found only small amounts of very fine particles were produced, with negligible redistribution and little damage. This is the result of the nature of the drilling process, and most of the damage was confined to the perforated tunnel, causing only a slight blockage of flow. Therefore, we assumed that the created samples were ideal perforations and did not have a crush zone around the perforation. The shape and dimensions of two artificial sandstone samples are explained in Figs. 1 and 2 .

Currently, mercury intrusion porosimetry (MIP) is one of the common techniques used to analyze sandstone samples' main index properties and pore morphologies. The porosimeter uses a specialized pressure chamber as a means to force the mercury to fill porous substrate voids. Being forced by pressure, the mercury intrudes larger pores and then, under increasing pressure, starts intruding smaller pores (Giesche, 2006). Using this approach, 

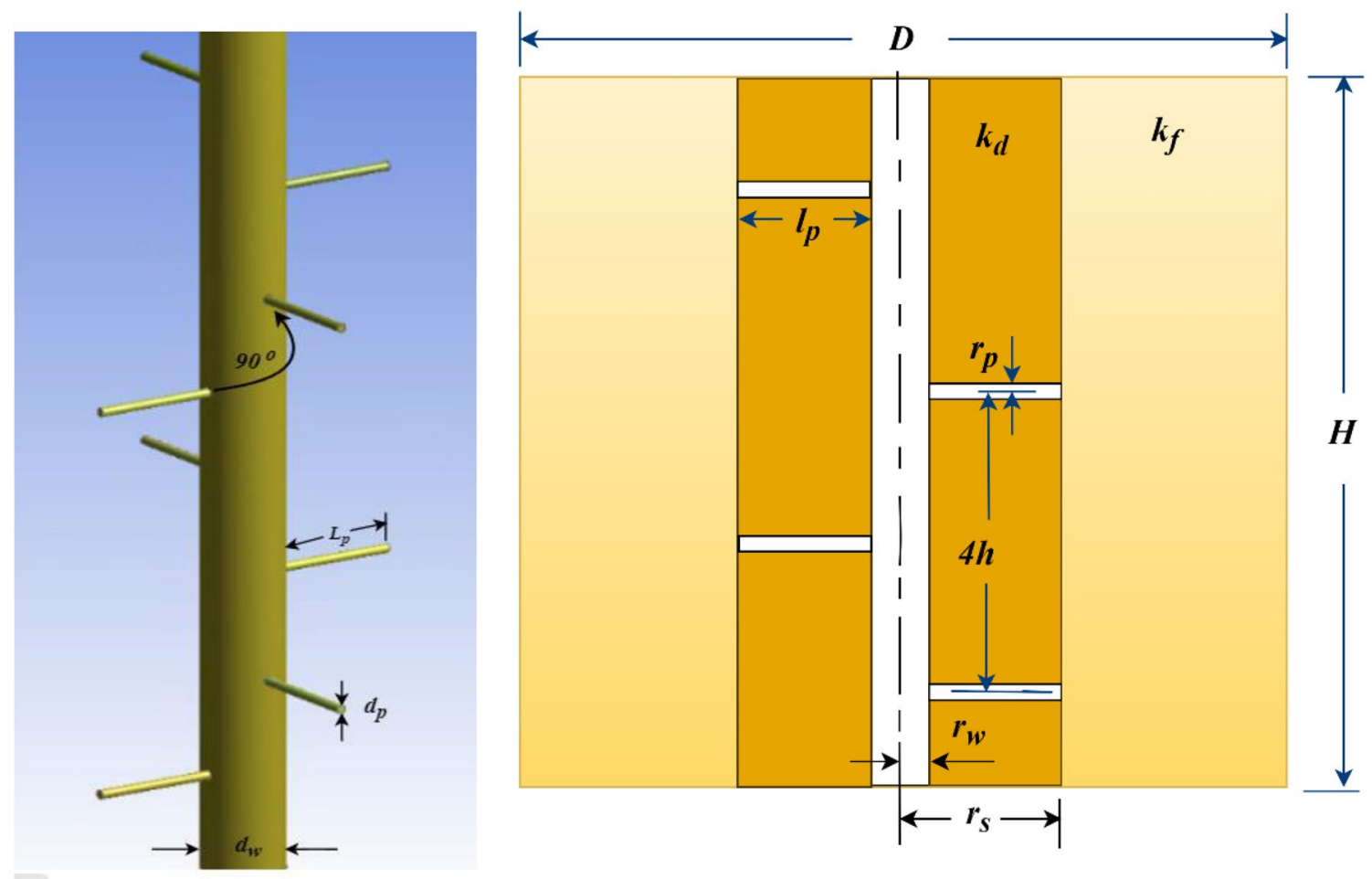

Fig. 2 The dimensions of artificial sandstone samples

it is possible to characterize both intra- and inter-particle pores. MIP was used first to characterize and then analyze the pore morphology and index properties for the two zones in the artificial samples.

\section{Experimental procedure}

In the present study, we used the experimental setup initially designed and built by Ahammad et al. (2018 and 2019) as a radial flow cell (RFC); the RFC was created for the purpose of carrying out experiments under wellbore conditions. Figure 3 shows the RFC setup, which includes three main sections: flow lines extending from inlet to outlet, an inner chamber for holding samples with axial loads, and a data acquisition (DQ) system.

From a literature review, we can see that experiments carried out on perforation methods have mostly relied on rather simplistic assumptions; our experiments carried out on simplistic assumptions, such as those presented by Rahman et al. (2007a and 2007b). Moreover, as a result of laboratory constraints, the majority of the experimental investigations in the published literature have neglected key reservoir characteristics such as thermal effects, drawdown pressure, and actual reservoir pressure. In the experimental portion of our work, we injected a measured volume of water of a single-phase into our two samples; three value flow rates $(1,2$, and 3 Liter/minute) of water were injected through each sample within Darcy's flow range. Water was used instead of oil as water does not cause permanent damage to the samples. RFC setup was used to measure the differential pressure and flow rates, with the water radially injected into our core sample for the single flow within the different flow rates.

\section{Numerical simulation procedure}

In the present work, ANSYS FLUENT 18.1 was used for numerical simulations of fluid flow through a near-wellbore region. Our aim was to present a single-phase fluid flow simulation for a reservoir described as three-dimensional, vertical, and cylindrically layered. We created a sample that is vertical with a single layer of uniform thickness. Next, we assumed the well was centrally located and had a drilled radius $\left(r_{w}\right)$ throughout the formation. Further, the well was perforation completed and also had a horizontal-to-vertical permeability ratio $\left(k_{h} / k_{v}\right)$. Hence, we could apply the conditions and assumptions enumerated below in developing our model:

1. The medium is anisotropic and porous, of uniform thickness, and is constantly permeable (i.e., features constant vertical permeability that is nonzero). 


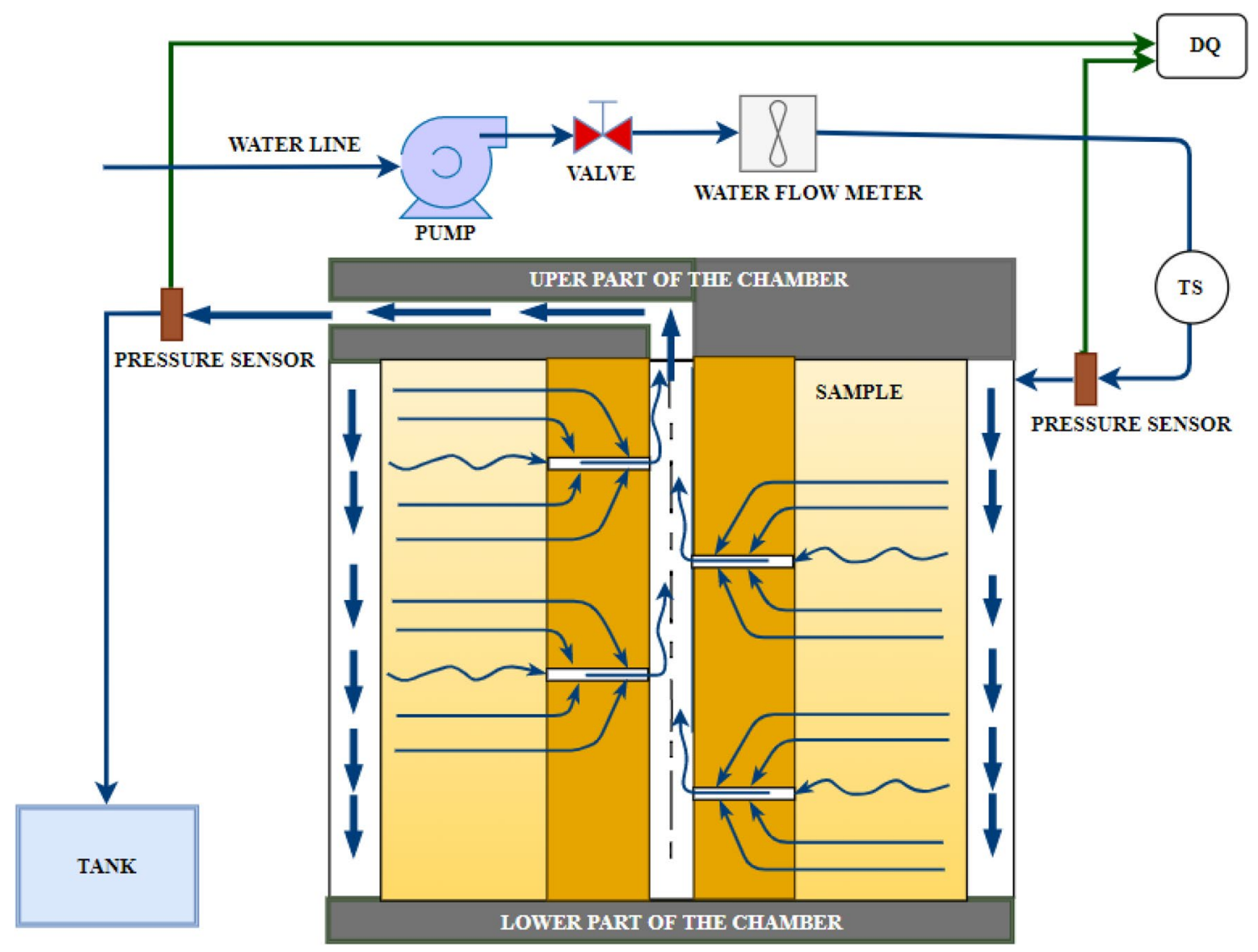

Fig. 3 The schematic diagram of RFC for single-phase water

2. The flow through the reservoir can be described as single-phase water, and either radial-vertical laminar or Darcy's flow.

3. Any flux proceeding into the well features uniform distribution across perforated intervals.

4. Thermal effects are ignored.

5. Although perforation skin has been considered in the present research, other skin factors have not.

6. The perforations are assumed to be ideal without formation damage and a crushed zone.

In the numerical work, we injected a measured volume of water into the cylindrical sample. The outer side of the sample was considered an inlet, and the wellbore surface was an outlet in the open hole completion case, while the perforations' surface was taken as an outlet in the perforated casing completion case. The uniform mesh and cut mesh methods were utilized to produce a high mesh density, as shown in Fig. 4. This arrangement contributed to capturing the significant pressure gradients around the border regions.

Fluid flow in a near-wellbore region undergoes many measures of physical changes, such as pressure drop due to friction losses around the perforations, gravity, acceleration, and

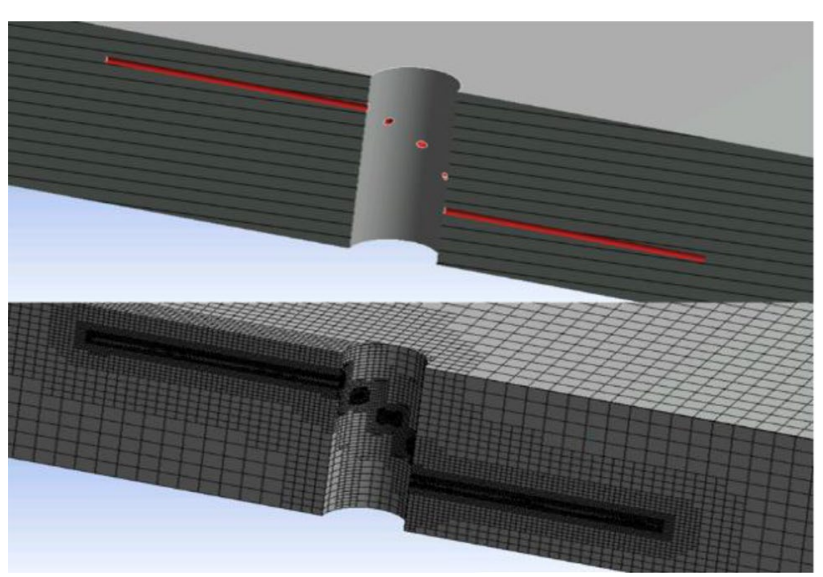

Fig. 4 Vertical section for the outlet and the shape of uniform configuration mesh

density of a fluid. In order to properly determine these physical changes, the two governing equations (mass and momentum equations) of fluid flow are needed to represent mathematical models of the conservation of physical laws. The conservation equations for mass and momentum describing single-phase 
flow in a porous region could be expressed, respectively (Sun et al. 2013) as:

$\frac{\partial \gamma \rho}{\partial t}+\nabla \cdot(\gamma \rho \vec{v})=0$

$\frac{\partial}{\partial t}(\gamma \rho \vec{v})+\nabla \cdot(\gamma \rho \vec{v} \vec{v})=-\gamma \nabla p+\nabla \cdot(\gamma \overline{\bar{\tau}})+\gamma \vec{B}_{f}-\left(\frac{\mu}{k} \vec{v}+-\frac{C_{2}}{2} \rho|\vec{v}| \vec{v}\right)$

The last term in Eq. (20) represents the viscous and inertial loss imposed by the porous media on the fluid. The laminar flows in porous media generally feature a pressure drop proportional to permeability and velocity. By ignoring out an inertial loss term, we can reduce the porous media model to Darcy's law, as expressed in the equation:

$\nabla p=-\frac{\mu}{k} \vec{v}$

\section{Statistical procedure}

In the present work, we used Design of Experiments software (DoE) with Box-Behnken design (BBD) in designing the numerical runs needed for statistical analysis. The initial step in DoE is the identification of independent variables and/or factors that may have an effect on the outcomes. The next step involves identifying the dependent variables and/ or factors (Davim, 2016). The BBD, described as a response surface methodology (RSM) design, requires only three levels in its experimental or numerical runs (Box \& Cox, 1964). The model is then statistically validated through analysis of variance (ANOVA) (Box and Behnken 1960; Ferreira, et al. 2007). Based on these initial processes, four dimensionless parameters were investigated, including the penetration ratio $\left(P_{r}\right)$, radius ratio $\left(R_{r}\right)$ permeability ratio $\left(k_{r}\right)$ and the ratio of perforation angle to $180^{\circ}\left(\theta_{d}\right)$ :

$P_{r}=\frac{l_{p}}{h_{p}}$

$R_{r}=\frac{r_{p}}{r_{w}}$

$K_{r}=\frac{k_{h}}{k_{v}}$

$\theta_{d}=\frac{\theta}{180}$

Two boundary points were selected, and one midpoint was determined by BBD for the intervals of the four
Table 4 The range of dimensionless parameters

\begin{tabular}{ll}
\hline Dimensionless parameters & Range \\
\hline Penetration ratio $(P r)$ & $1.333-8$ \\
Ratio of perforation radius to wellbore radius $(R r)$ & $0.025-0.2$ \\
Permeability ratio $(K r)$ & $1-10$ \\
Ratio of perforation angle to $180^{\circ}\left(\theta_{d}\right)$ & $0.33-1$ \\
\hline
\end{tabular}

Table 5 The main index properties of the samples

Index properties of the two artificial samples' zones Values (units) (S1 and S2)

\begin{tabular}{ll}
\hline Permeability of skin zone $\left(k_{d}\right)$ & 6.3 Darcy \\
Porosity of skin zone $\left(\gamma_{s}\right)$ & $26 \%$ \\
Permeability of formation zone $\left(k_{f}\right)$ & 26.6 Darcy \\
Porosity of formation zone $\left(\gamma_{f}\right)$ & $21 \%$ \\
\hline
\end{tabular}

dimensionless parameters, as presented in Table 4. Statistical analysis was applied to determine the impact of each dimensionless parameter on the perforation skin factor value in two cases. In the first case, the effect of three dimensionless parameters $\left(P_{r}, R_{r}\right.$ and $\left.K_{r}\right)$ on the perforation skin factor was analyzed at the perforation angle $\left(360^{\circ}\right)$. In the second case, the same procedure was followed as in the first case with a range of perforation angles $\left(60^{\circ}-180^{\circ}\right)$. Thirty-six numerical runs in two cases were performed to obtain a suitable statistical analysis using the ANOVA analysis with the BBD model.

\section{Results and discussion}

The four investigative methods of sample preparation, experimental, numerical, and statistical analysis were used to analyze the interaction among the perforations' parameters and their effect on the pressure gradient in the near-wellbore region. For the samples' preparation, MIP techniques was used to obtain the main index properties (permeability and porosity) and to make sure the artificial samples are homogeneous. MIP measurements of the two artificial sandstone zones (S1 and S2) showed high values for permeability and porosity, as illustrated in Table 5. Using MIP experimental data, Fig. 5 shows the pore size distribution (PSD) curves as pore throat diameter vs. pore volume $(\mathrm{dV} / \mathrm{d} \log \mathrm{D})$ for the two artificial sandstone zones. The two artificial sandstone zones' PSD curves show single peaks, which means that the two sandstone samples have homogeneous pore size distributions. Moreover, pore sizes are mainly in the range of 50 to $350 \mu \mathrm{m}$.

The statistical analysis was coupled with numerical simulation to expand fluid flow investigation in the 
Fig. 5 Pore size distribution (PSD) curves of the two artificial sandstone zones

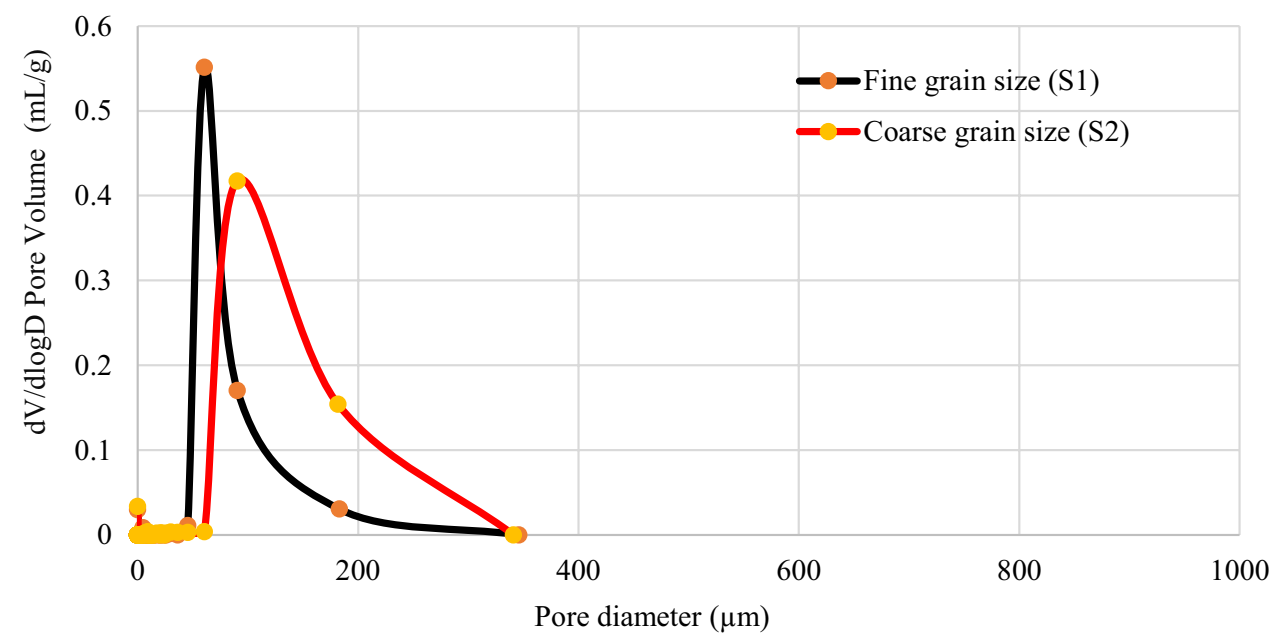

Table 6 Dimensionless parameters of two artificial samples and flow boundary conditions

\begin{tabular}{ll}
\hline $\begin{array}{l}\text { Dimensionless parameters and flow boundary } \\
\text { conditions }\end{array}$ & Values (units) \\
\hline Penetration ratio $\left(P_{r}\right)$ & 1 \\
Ratio of perforation radius to wellbore radius & 0.11811 \\
$\quad\left(R_{r}\right)$ & 1 \\
Permeability Ration $\left(K_{r}\right)$ & $90^{\circ}$ \\
Perforation angle $(\theta)$ & 1,2 and $3 \mathrm{~L} / \mathrm{min}$ \\
Three water flow rates $(Q)$ & $0.00095 \mathrm{~kg} / \mathrm{m} \cdot \mathrm{s}$ \\
\hline Viscosity of water $(\mu)$ & \\
\hline
\end{tabular}

near-wellbore region and analyze the results. For perforated wells, fluids can come into the wellbore via perforation tunnel arrays. The perforations are usually created around the wellbore helically (i.e., shaped like a helix or spiral). The CFD simulation results have been validated with experimental data for the injection build-up pressure through the open hole sample and the perforated casing sample at the same flow boundary conditions (Table 6). The comparison between the experimental data and numerical results for the single-phase flow (water) through the two artificial samples is shown in Figs. 6 and 7. The results of validation showed a good agreement between the numerical results and experimental data.

The comparison results showed that the perforated sample strongly affects the injection pressure build-up, due to the casing resistance, by forcing the flow to pass only through the perforations. Also, the results exhibited that the pressure build-up takes a short time to reach steady-state condition; this time decreases with increasing water flow rate $(Q)$. In the low flow rate cases, the required time for reaching steady-state conditions is longer than the high flow rate case due to the samples' large storage capacity; a high portion of the fluid will pass through the perforations, and a small portion will be stored within the pores. In addition, the results show a slight deviation between the experimental and numerical results that appear in higher flow rate cases. This may be related to the resistance of small damage or amounts
Fig. 6 The comparison between experimental data and numerical simulation results for a single-phase (water) flow at the different flow rates through the open hole artificial sample

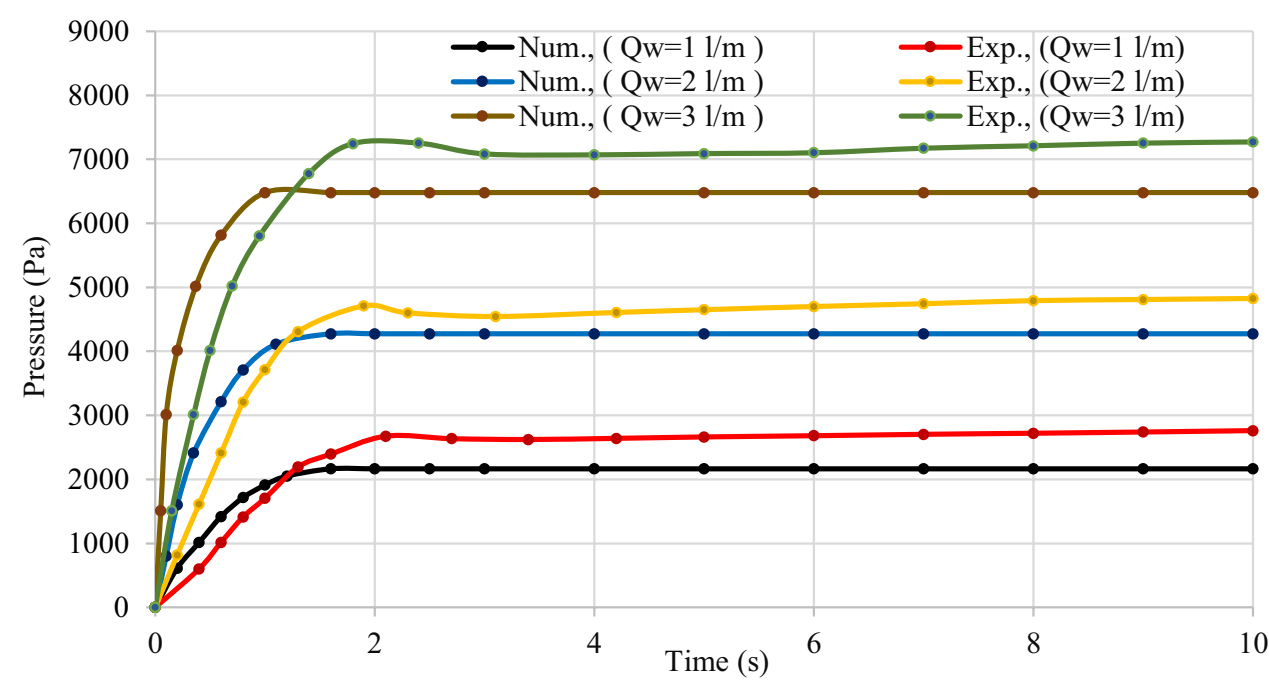


Fig. 7 The comparison between experimental data and numerical simulation results for a single-phase (water) flow at the different flow rates through the casing perforated artificial sample

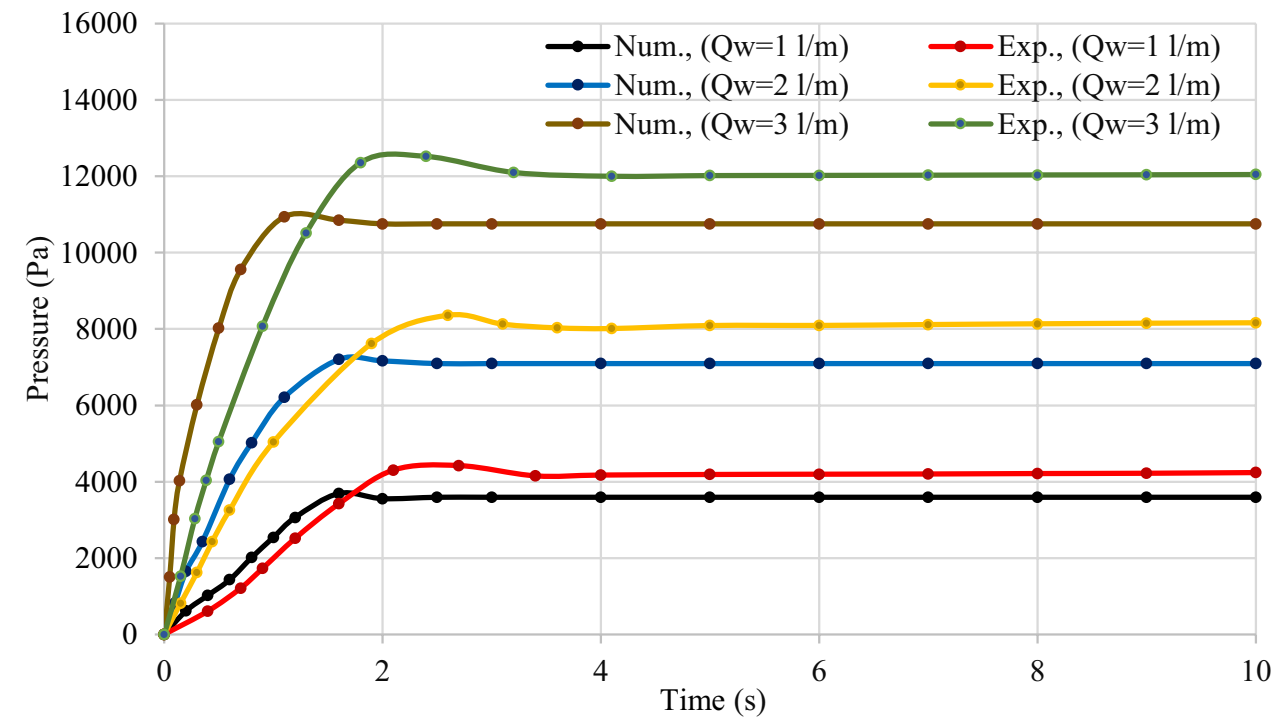

of very fine particles around the perforations produced by the PD technique.

The perforation skin factor was obtained from the difference for pressure drop results between the two completion samples in both experimental and numerical methods. The numerical results exhibit a clear view of the effect of perforation parameters on the value and distribution of pressure gradient for the single flow water at the same flow boundary condition. For example, the perforation skin factor value for one of the numerical run cases was calculated; it was close to zero due to the similar pressure gradient results in both cases (an open hole and perforated sample), as shown in Figs. 8 and 9.
The present study provides an in-depth analysis of perforated well completion productivity. As part of the analysis, dimensionless groups were identified that control flows within the perforations, along with the effects of these groups on wells' productivity. Furthermore, using numerical and statistical analyses, a series of results were obtained that highlight the examined well's perforation skin factor. The statistical analysis results show a clear view of the interaction effect among the four dimensionless parameters $\left(P_{r}, R_{r}, K_{r}\right.$ and $\left.\theta_{d}\right)$ on the perforation skin factor $\left(S_{p}\right)$ for two perforation angle cases $\left(360^{\circ}\right.$ and $\left.60^{\circ}-180^{\circ}\right)$, as illustrated in Figs. 10 and 11. The results indicate that the increasing penetration ratio $\left(P_{r}\right)$ decreased the perforation skin factor

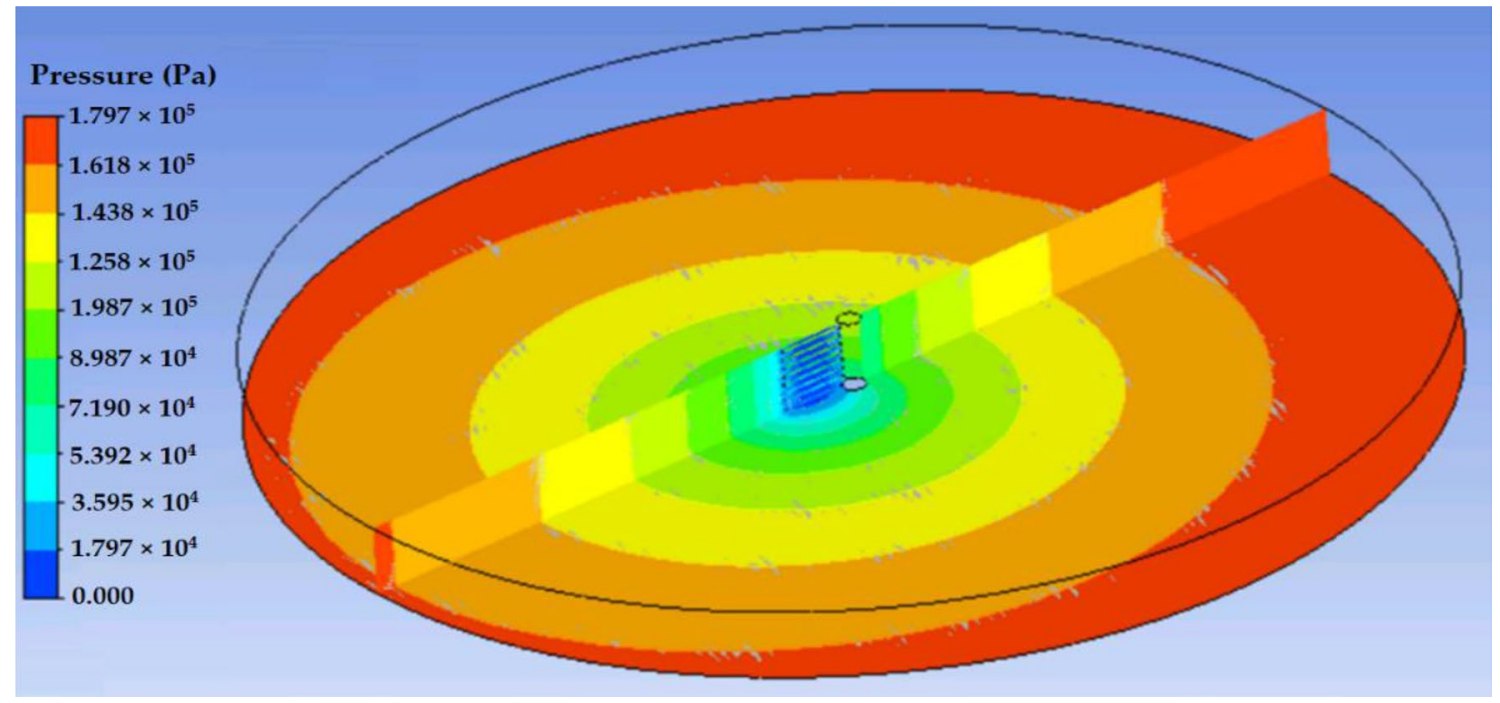

Fig. 8 Numerical results of the pressure gradient for perforated completion case at boundary conditions $(Q=11 / \mathrm{min}, \mu=0.001003 \mathrm{~kg} / \mathrm{m} \cdot \mathrm{s}$, $r_{e}=10 \mathrm{~m}, r_{w}=0.1 \mathrm{~m}, \gamma=20 \%, P_{r}=8, R_{r}=0.1125, K_{r}=1$, and $\theta=360^{\circ}$ ) 


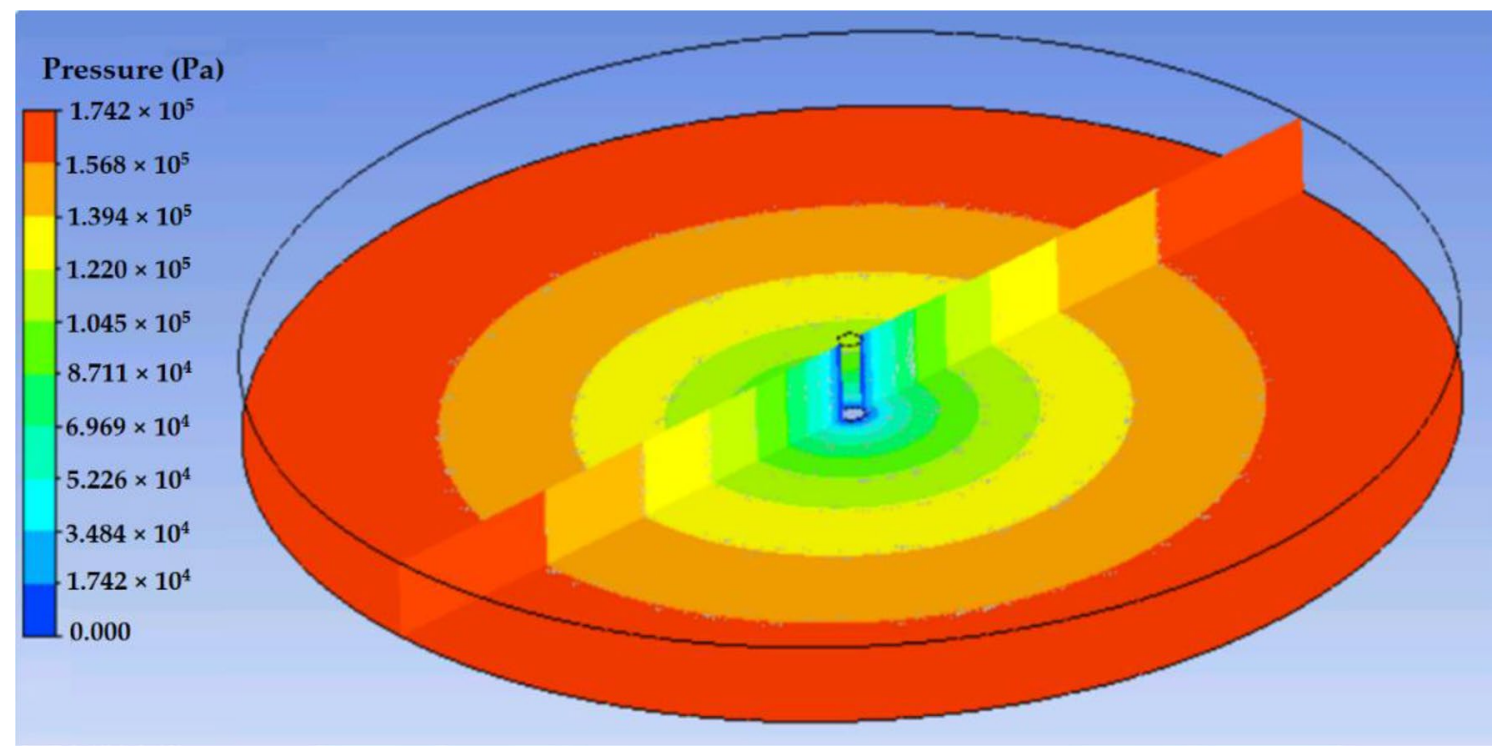

Fig. 9 Numerical results of the pressure gradient for open hole completion at boundary conditions $\left(Q=11 / \mathrm{min}, \mu=0.001003 \mathrm{~kg} / \mathrm{m} \cdot \mathrm{s}, r_{e}=10 \mathrm{~m}\right.$, $\left.r_{w}=0.1 \mathrm{~m}\right)$

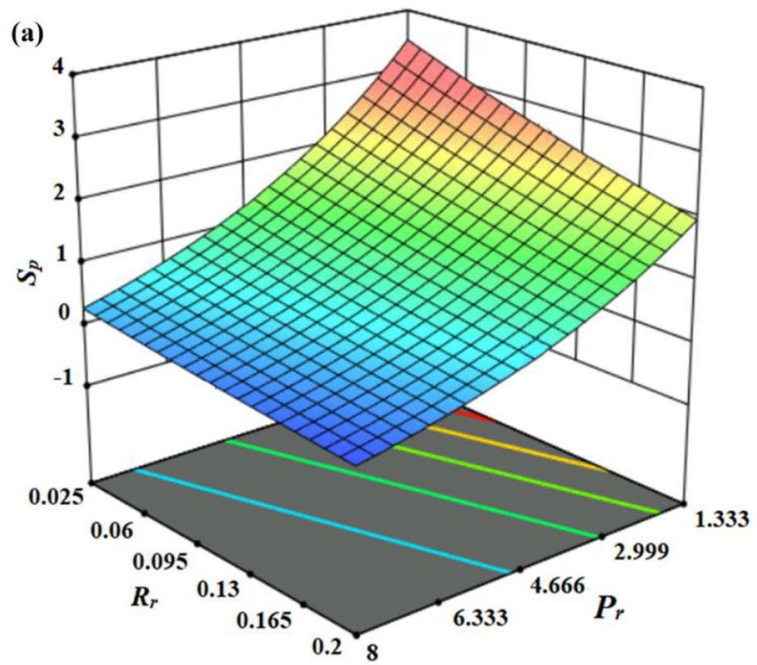

Fig. 10 Interaction of the three dimensionless parameters $\left(P_{r}, R_{r}\right.$ and $\left.K_{r}\right)$ and their effects on the perforation skin factor $\left(S_{p}\right)$ at perforation angle $\theta=360$ : (a) Interaction between the two dimensionless parameters $\left(P_{r}\right.$ and $\left.R_{r}\right)$ with constant value for the dimensionless param-

due to the high radial flow rate. This means that if the perforations are long and the distance between them is short, the well productivity will be significantly increased. If the penetration ratio is low, the rise in perforation skin factor will be higher. In this case, due to high resistance, higher injection pressure would be necessary to inject the required volume in the core sample. Therefore, long perforations, together with high perforation density, will decrease the perforation

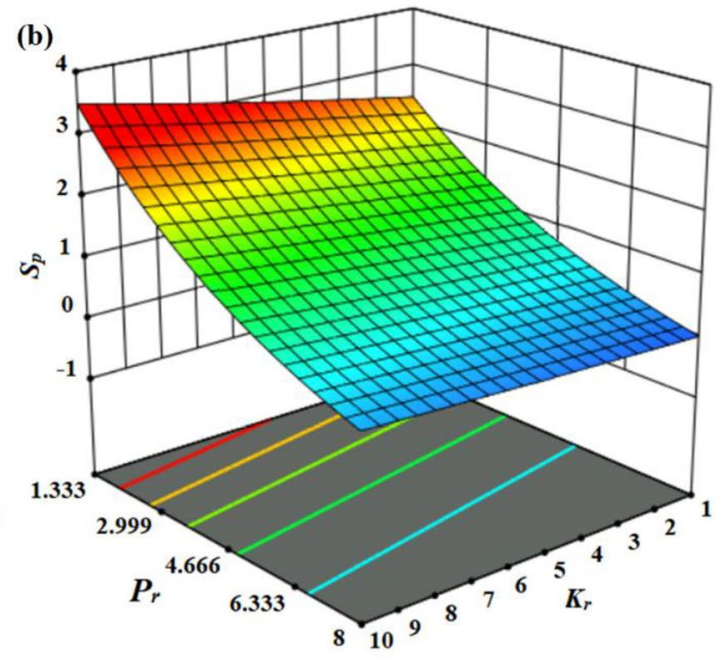

eter $\left(K_{r}=10\right)$; (b) Interaction between the two dimensionless parameters $\left(P_{r}\right.$ and $\left.K_{r}\right)$ with constant value for the dimensionless parameter $\left(R_{r}=0.025\right)$

skin factor's value and increase the radial flow in the nearwellbore region.

In addition, the ratio of perforation radius to wellbore radius $\left(R_{r}\right)$ and permeability ratio $\left(K_{r}\right)$ have a moderate effect, while the ratio of perforation angle $\left(\theta_{d}\right)$ has a low impact on the perforation skin factor value. The increase in $R_{r}$ shows a moderate contribution to productivity, which indicates that perforation aperture widening for enhancing 

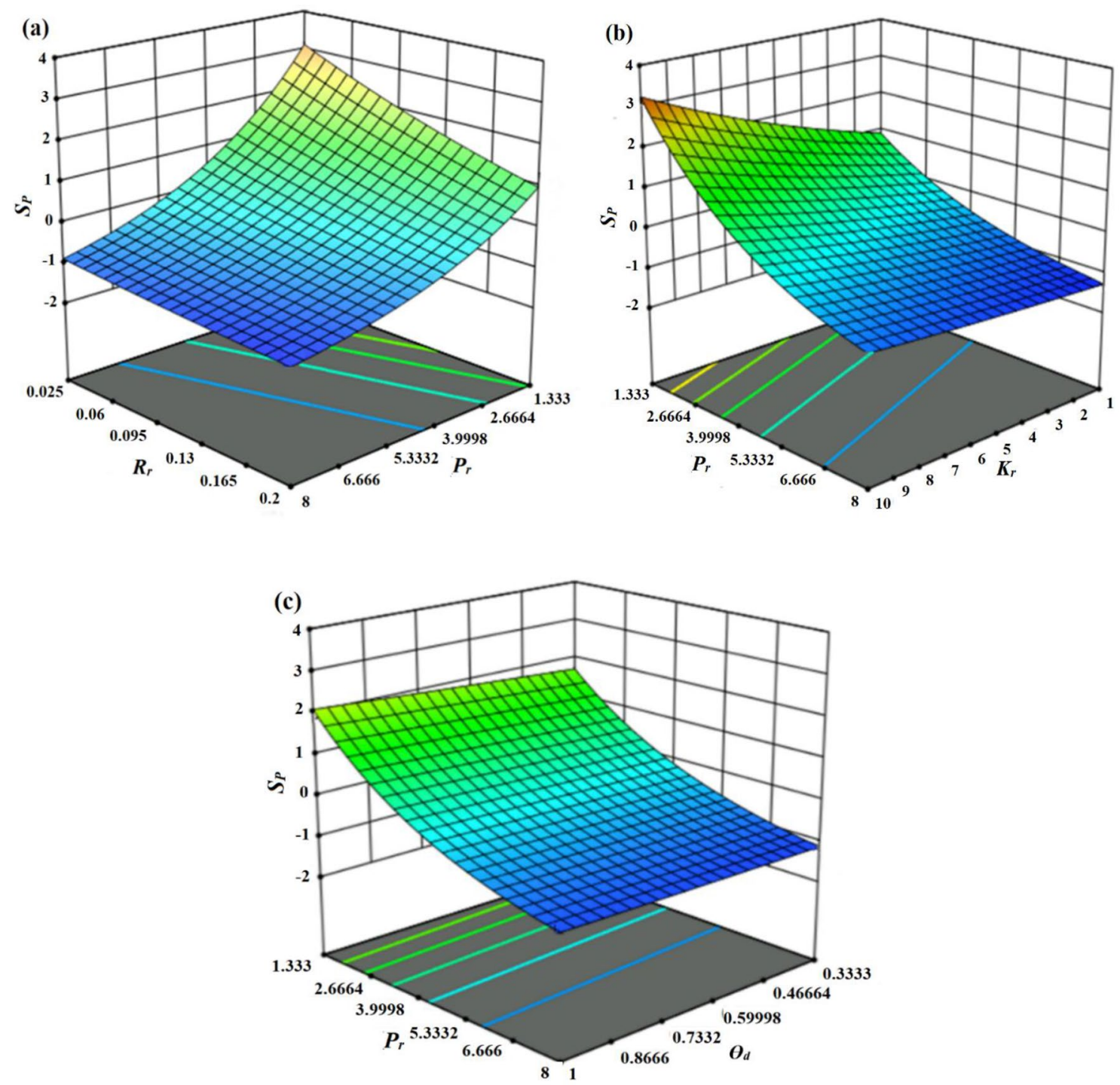

Fig. 11 Interaction of the three dimensionless parameters $\left(P_{r}, R_{r}, K_{r}\right.$ and $\left.\theta_{d}\right)$ and their effects on the perforation skin factor $\left(S_{p}\right)$ at perforation angles $\theta=60$ - 180: (a) Interaction between the two parameters $\left(P_{r}\right.$ and $\left.R_{r}\right)$ with constant value for $K_{r}=5.5$ and $\theta_{d}=0.666$; (b) Interaction between

bottom flow accomplishes relatively little. For vertical wells, the reservoir anisotropy's effect on productivity ratio is also tested in this work, showing that the productivity ratio generally declines with increasing the horizontal-vertical-permeability ratio $\left(k_{h} / k_{v}\right)$. The skin factor for different perforation angles is reduced when the inflow angle decreases, whereas maximum value is achieved at a perforation angle of $360^{\circ}$, as illustrated in Fig. 10.

We can learn the effect of each perforation parameter from these results and, based on the results, choose the design that is optimal. This means choosing the best the two parameters $\left(P_{r}\right.$ and $\left.K_{r}\right)$ with constant value for $R_{r}=0.1125$ and $\theta_{d}=0.666$; (c) Interaction between the two parameters $\left(P_{r}\right.$ and $\left.\theta_{d}\right)$ with constant value for $R_{r}=0.1125$ and $K_{r}=5.5$

perforation technique that will lead to a high flow rate, as well as choosing the best density and dimensions for the perforation as a means to accelerate radial inflow. The overall outcome of these informed choices is an increase in the productivity index.

The current correlations used for simulating production flows in perforated vertical wells require a relatively complex process involving tables and equations to calculate perforation skin factor. Aiming to streamline this process, the present work proposed efficient and simple correlations for simulating the flows in the near-wellbore region that have 
helical and symmetrical perforations. Two correlations were obtained from the statistical analysis based on the experimental and numerical results for the two cases:

$S_{p}\left(360^{\circ}\right)=10^{\left(0.65-0.08756 P_{r}-1.069 R_{r}+0.01312 K_{r}\right)}-0.85$

$S_{p}\left(60^{\circ}-180^{\circ}\right)=10^{\left(0.655-0.1123 P_{r}-1.428 R_{r}+0.0302 K_{r}+0.0703 \theta_{d}\right)}-1.75$

The two correlations are used to determine the effect of the four dimensionless parameters on the perforation skin factor value. A comparison of perforation skin factor results for obtained correlations and results of the available model (Karakas and Tariq (1991)) was performed to verify their computational accuracy and efficiency, as shown in Figs. 12, 13, 14 and 15. The comparison results demonstrated good agreement between the current correlations and Karakas and Tariq's semi-analytical model results within the range of dimensionless parameters (see Table 4). In addition, two novel correlations have been produced from the current study that simplify the estimation of the perforation skin factor in perforation wells compared to the available model. The correlations can be used to calculate the perforation skin factor by integrating the horizontal-flow effect, the vertical converging effect, and the wellbore effect.
Fig. 12 The comparison between Karakas and Tariq's model and the obtained correlation results of increasing the penetration ratio $\left(P_{r}\right)$ on the perforation skin factor at perforation angle $360^{\circ}$

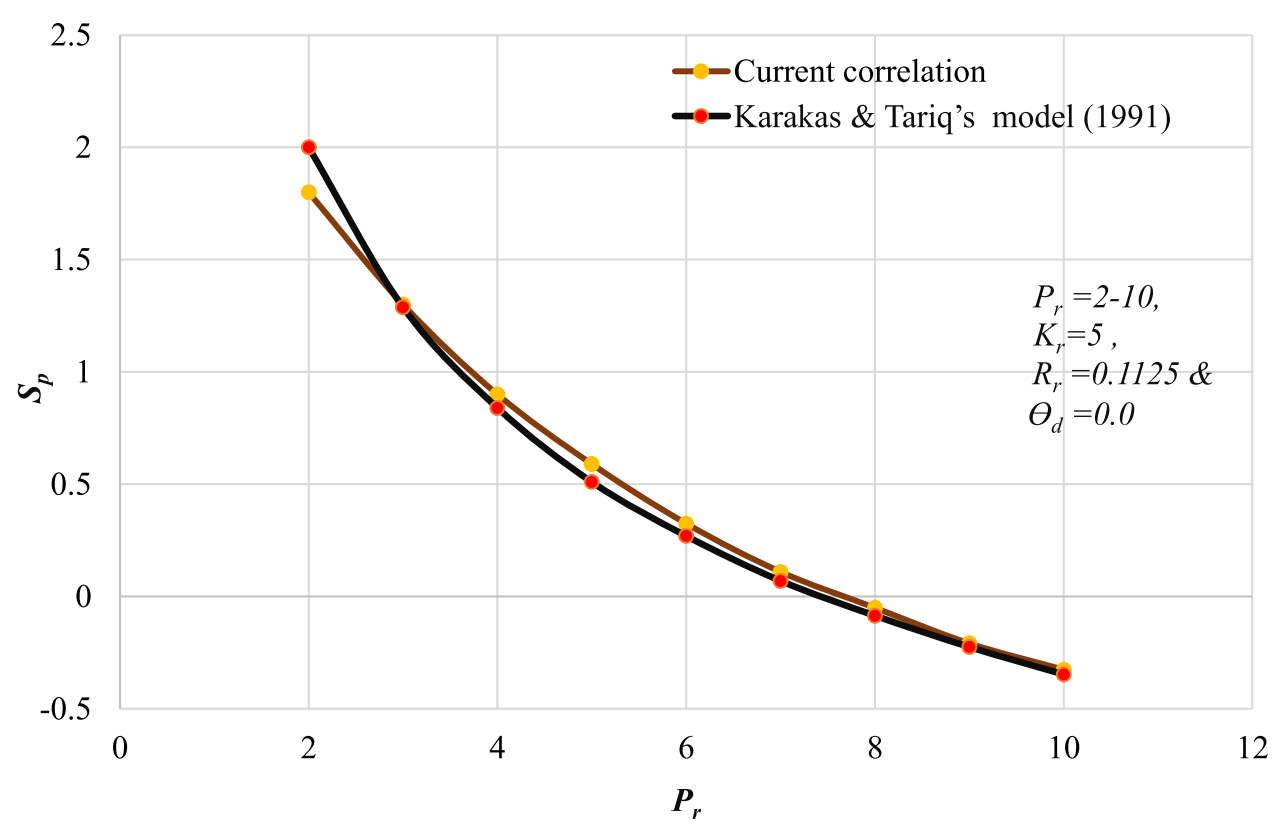

Fig. 13 The comparison between Karakas and Tariq's model and the obtained correlation results of increasing the penetration ratio $\left(P_{r}\right)$ on the perforation skin factor at perforation angle $60^{\circ}$

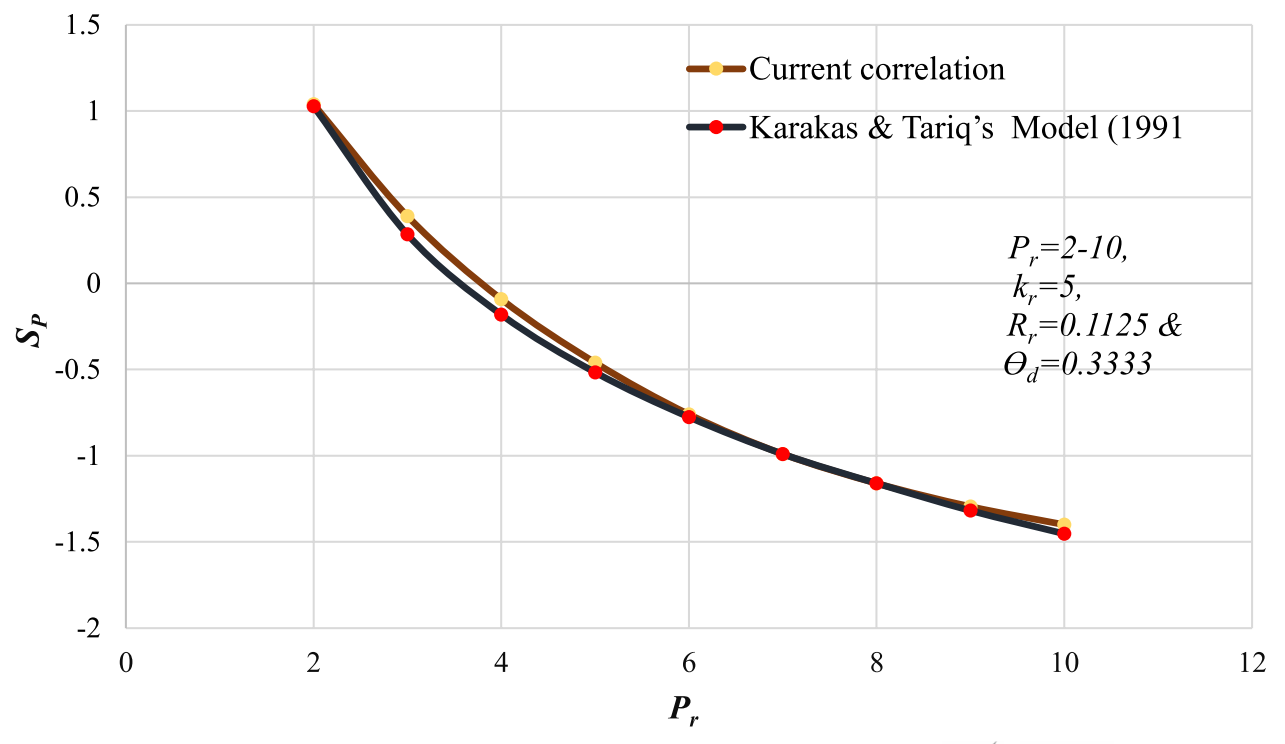


Fig. 14 The comparison between Karakas and Tariq's model and the obtained correlation results of increasing the penetration ratio $\left(P_{r}\right)$ on the perforation skin factor at perforation angle $120^{\circ}$
Fig. 15 The comparison between Karakas and Tariq's model and the obtained correlation results of increasing the penetration ratio $\left(P_{r}\right)$ on the perforation skin factor at perforation angle $180^{\circ}$
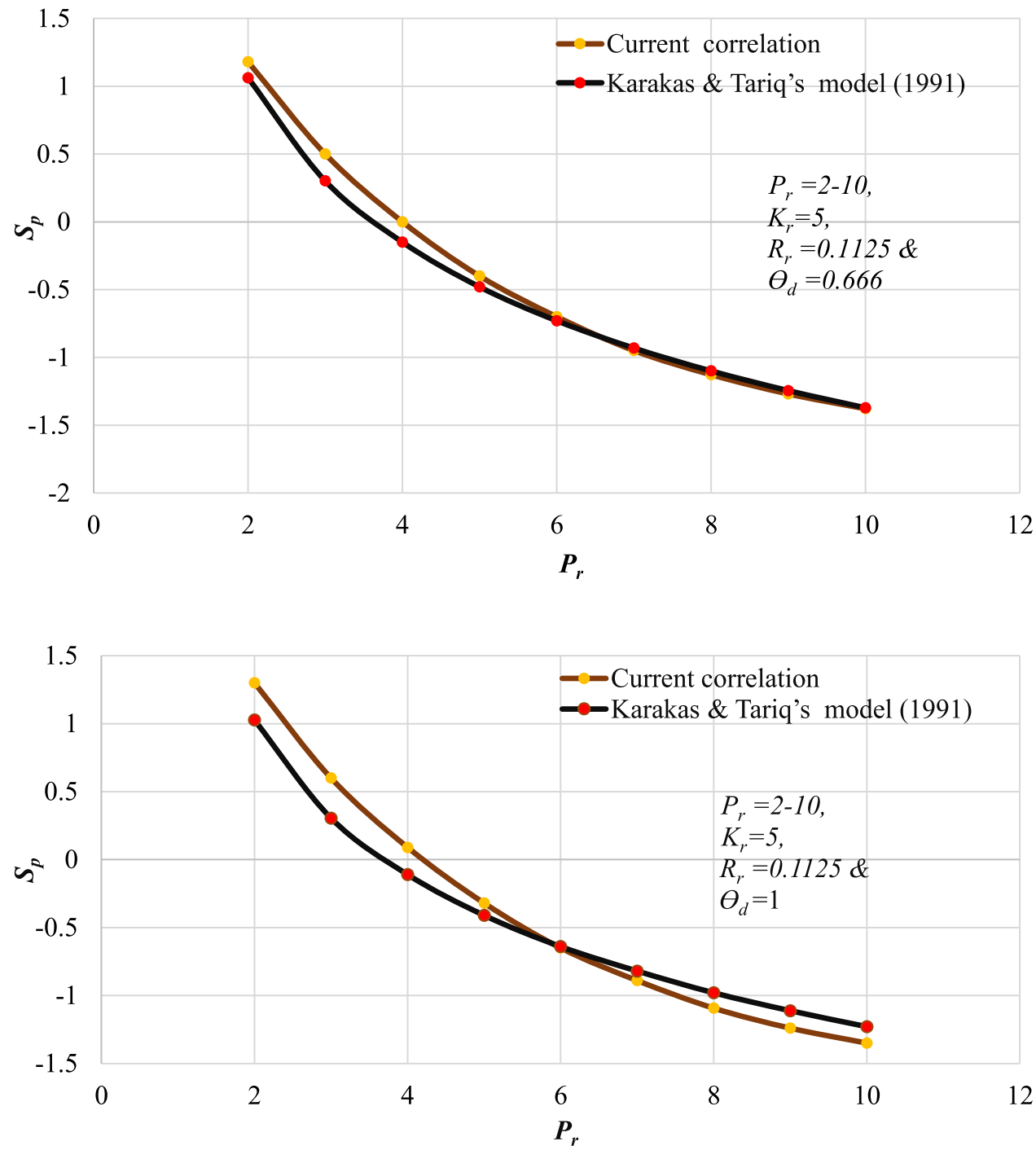

Fig. 16 Effect of penetration ratio $\left(P_{r}\right)$ on productivity ration $\mathrm{PR}$ at different perforation angles $\left(60^{\circ}-360^{\circ}\right)$

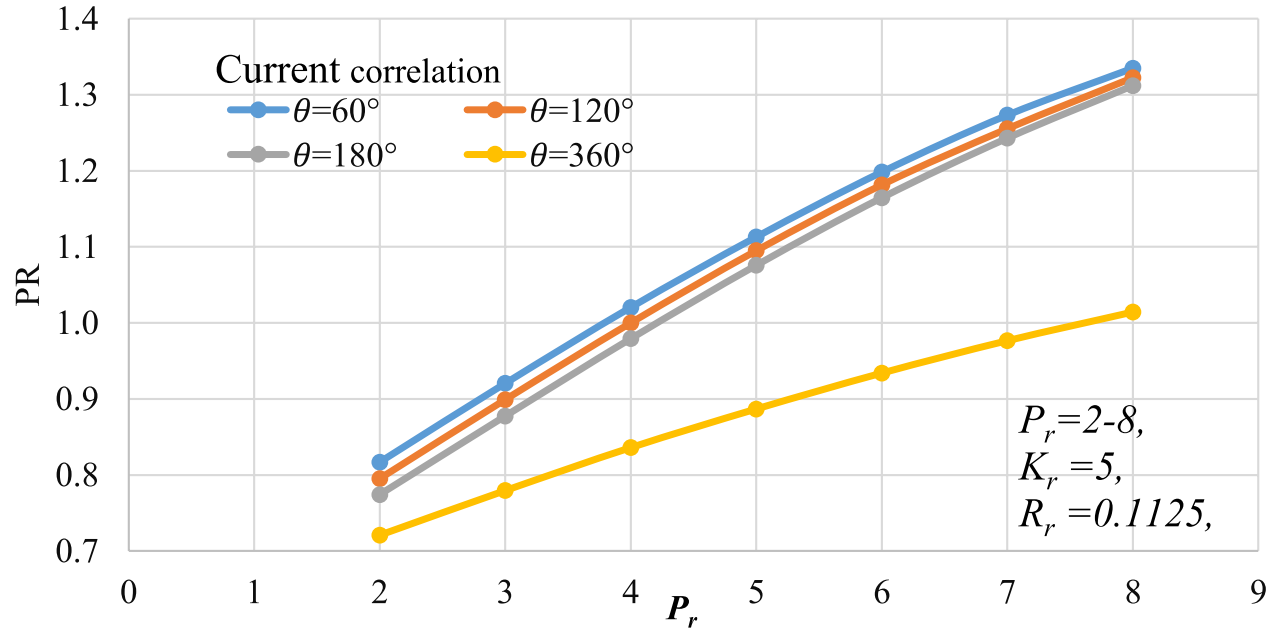


Fig. 17 Effect of ratio of perforation radius to wellbore radius $\left(R_{r}\right)$ on productivity ration $\mathrm{PR}$ at different perforation angles $\left(60^{\circ}-360^{\circ}\right)$

Fig. 18 Effect of permeability ratio $\left(K_{r}\right)$ on productivity ration $\mathrm{PR}$ at different perforation angles $\left(60^{\circ}-360^{\circ}\right)$
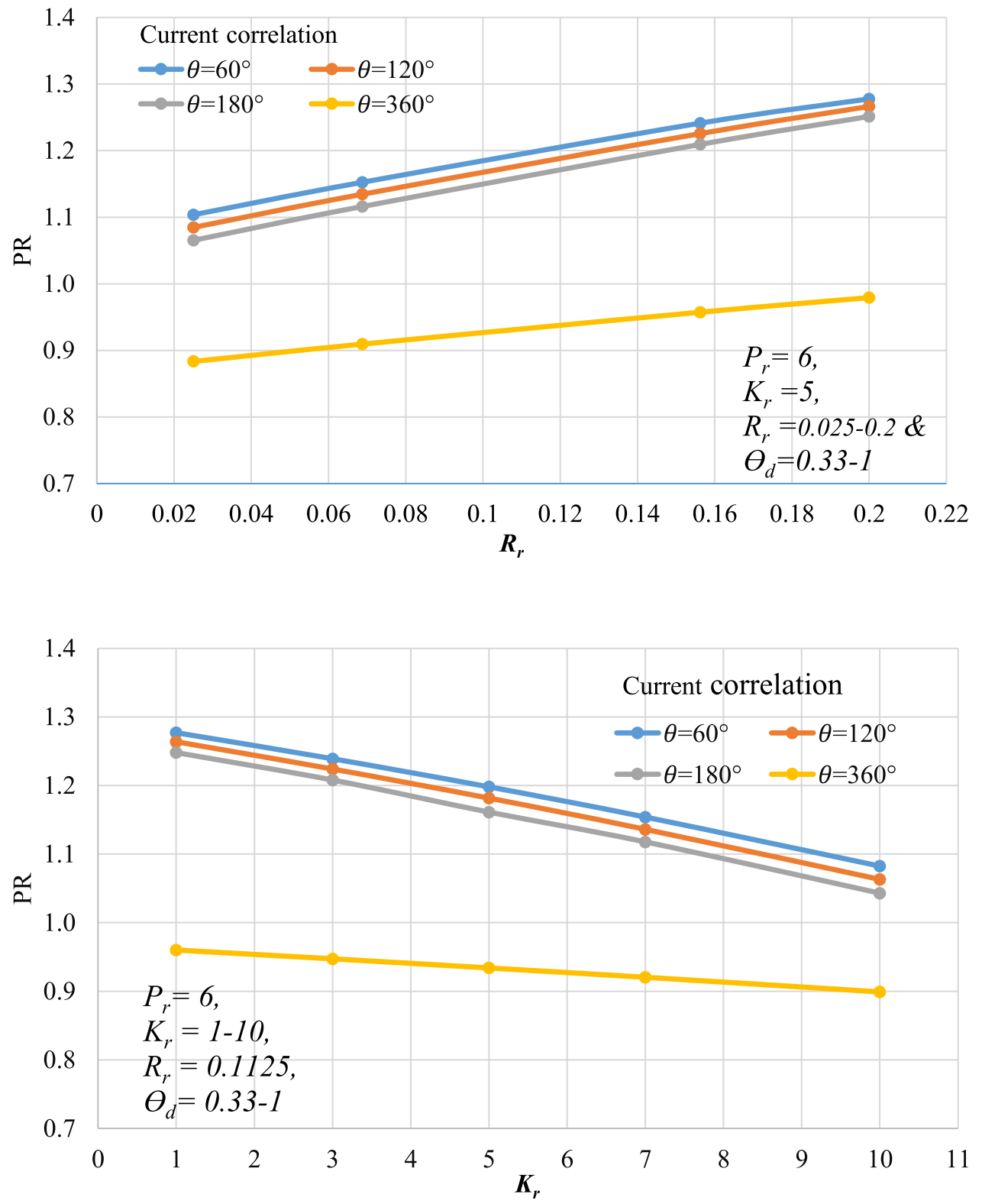

The productivity ratio (PR) is a function of perforation length to penetration space or perforation shot densities. The productivity improvements are shown by increasing the perforation's depth or using high perforation densities, as illustrated in Fig. 16. Also, the results showed a slight improvement for productivity by increasing the ratio of perforation radius to wellbore radius $\left(R_{r}\right)$, while increasing the permeability ratio $\left(K_{r}\right)$ leads to reduced productivity, as shown in Figs. 17 and 18. Additionally, the results demonstrated improvement in productivity by decreasing the perforation angle. The pressure drop in the near-wellbore region decreases at the small perforation angle cases due to the addition of flow conduits from multiple directions. The maximum production rate was found for perforation angles of $60^{\circ}$ degrees, likely due to the suitability of the flow convergence.

\section{Conclusion}

This work was conducted in order to expand the knowledge regarding the effect of perforated wells on the perforation skin factor and pressure gradient in a near-wellbore region. Based on experimental and numerical investigations, the following conclusions can be drawn:

1. The comparison results showed a good agreement between the experimental data and numerical results. Based on these results, extensive numerical investigations were conducted to evaluate the effect of the perforated casing completion on the pressure drop in the near-wellbore region. 
2. The numerical results exhibited a clear view of the effect of perforation parameters on perforation skin factor in the near-wellbore region. Therefore, choosing the optimal perforation parameters can be achieved, along with ways to boost productivity.

3. Two novel correlations have been produced from the current study that simplify the estimation of the perforation skin factor in the perforated casing completion. Compared to the available model:

(a) The comparison demonstrated good agreement between the current correlations and available model results within the range of the study's dimensionless parameters.

(b) The novel correlations work well by providing an accurate estimation for the perforation skin factor without using a lengthy procedure that includes many tables and equations.

Funding This publication was also made possible by the grant NPRP10-0101-170091 from Qatar National Research Fund (a member of the Qatar Foundation). Statements made herein are solely the responsibility of the authors.

\section{Declarations}

Conflict of interest The authors whose names are listed above certify that they have no known competing financial interests that could have appeared to influence the work reported in this manuscript.

Ethical Statements The authors certify that this work is original and has not been published and will not be submitted elsewhere for publication.

Open Access This article is licensed under a Creative Commons Attribution 4.0 International License, which permits use, sharing, adaptation, distribution and reproduction in any medium or format, as long as you give appropriate credit to the original author(s) and the source, provide a link to the Creative Commons licence, and indicate if changes were made. The images or other third party material in this article are included in the article's Creative Commons licence, unless indicated otherwise in a credit line to the material. If material is not included in the article's Creative Commons licence and your intended use is not permitted by statutory regulation or exceeds the permitted use, you will need to obtain permission directly from the copyright holder. To view a copy of this licence, visit http://creativecommons.org/licenses/by/4.0/.

\section{References}

Abobaker E, Elsanoose A, Khan F, Rahman MA, Aborig A, Noah K (2021a) A new evaluation of skin factor in inclined wells with anisotropic permeability. Energies 14(17):5585-5595. https://doi.org/ 10.3390/en14175585

Abobaker E, Elsanoose A, Khan F, Rahman M, Aborig A, Butt S (2021b) Comparison of crushed-zone skin factor for cased and peforated wells calculated with and without including a Tip-Crushed Zone effect. Geofluids 2021:1-13. https://doi.org/10.1155/2021/3689964
Ahammad MJ, Rahman M, Zheng L, Alam J, Butt S (2018) Numerical investigation of Two-phase fluid flow in a perforation tunnel. J Nat Gas Sci Eng 55:606-611

Ahammad MJ, Rahman MA, Butt SD, Alam JM (2019) An experimental development to characterise the flow phenomena at the NearWellbore Region. ASME 2019 38th International Conference on Ocean, Offshore and Arctic Engineering. Glasgow, Scotland, UK: Volume 8: Polar and Arctic Sciences and Technology; Petroleum Technology.

Behrmann L, Hughes K, Johnson A, Walton I (2002) New underbalanced perforating technique Iincreases completion efficiency and eliminates costly acid stimulation. The SPE Annual Technical Conference and Exhibition. Texas.

Box GE, Behnken DW (1960) Some new three level designs for the study of quantitative variables. Technometrics 2(4):455-475

Box GE, Cox DR (1964) An analysis of transformations. J Roy Stat Soc: Ser B (methodol) 26(2):211-243

Butt S (1999) Development of an apparatus to study the gas permeability and acoustic emission characteristics of an outburst-prone sandstone as a function of stress. Int J Rock Mech Min Sci 36(8):1079-1085

Byrne M, Jimenez M, Chavez J (2009) Predicting well inflow using computational fluid dynamics - closer to the truth? the 8th European Formation Damage Conference. Scheveningen- Netherlands.

Byrne M, Jimenez M, Rojas E, Chavez J (2010) Modelling well Inflow potential in three dimensions using computational fluid dynamics. The SPE International Symposium and Exhibition on Formation Damage Control. Louisiana, USA.

Byrne M, Jimenez M, Rojas E, Castillo E (2011) Computational fluid dynamics for reservoir and well fluid flow performance modelling. The SPE European Formation Damage Conference. Noordwijk-Netherlands.

Byrne M, Djayapertapa L, Watson K, Goodin B (2014) Complex completion design and Inflow prediction enabled by detailed numerical well modeling. the SPE International Symposium and Exhibition on Formation Damage Control. Lafayette, Louisiana, USA.

Darcy H (1956) Les Fontaines Publiques de la Ville de Dijon: Exposition et Application des Principes a Suivre et des Formulesa Employer dans les Questions de Distribution d'Eau.

Davim JP (2016) Design of experiments in production engineering. Springer, Cham

Economides MJ (2013) Petroleum production systems. Prentice Hall, Upper Saddle River, NJ

Economides MJ, Nolte KG (2000) Reservoir stimulation. Wiley, Chichester

Ferreira S, Bruns R, Ferreira H, Matos G, David J, Brandão G, dos Santos W (2007) Box-Behnken design: An alternative for the optimization of analytical methods. Anal Chim Acta 597(2):179-186

Giesche H (2006) Mercury Porosimetry: A General (Practical) Overview. Part Part Syst Charact 23(1):9-19

Harris M (1966) The effect of perforating on oil well productivity. J Petrol Technol 18(04):518-528

Holt R, Brignoli M, Kenter C (2000) Core quality: Quantification of coring-induced rock alteration. Int J Rock Mech Min Sci 37(6):889-907

Karakas M, Tariq S (1991) Semianalytical productivity models for perforated completions. SPE Prod Eng 6(01):73-82

Klotz J, Krueger R, Pye D (1974) Effect of perforation damage on well productivity. J Petrol Technol 26(11):1303-1314

Locke S (1981) An advanced method for predicting the productivity ratio of a perforated well. J Petrol Technol 33(12):2481-2488

Molina O, Tyagi M (2015) A computational fluid dynamics approach to predict pressure drop and flow behavior in the near wellbore region of a frac-packed gas well. ASME 2015 34th International Conference on Ocean, Offshore and Arctic Engineering, 10. St. John's, Newfoundland, Canada. 
Rahman MA (2008) Scale-up of perforation process from laboratory model to bottom hole dimensions. J Porous Media 11(1):19-34

Rahman M, Mustafiz S, Biazar J, Koksal M, Islam M (2007a) Investigation of a novel perforation technique in petroleum wells-perforation by drilling. J Franklin Inst 344(5):777-789

Rahman M, Mustafiz S, Koksal M, Islam M (2007b) Quantifying the skin factor for estimating the completion efficiency of perforation tunnels in petroleum wells. J Petrol Sci Eng 58(1-2):99-110

Rahman MA, Heidrick T, Fleck B, Koksal M (2006) Enhancement of the completion efficiency of perforation tunnels in petroleum wells. ASME 2006 2nd Joint U.S.-European Fluids Engineering Summer Meeting Collocated With the 14th International Conference on Nuclear Engineering. Miami, Florida, USA.

Renpu W (2011) Basis of well completion engineering. Advanced Well Completion Engineering, 1-74.

Sun D, Li B, Gladkikh M, Satti R, Evans R (2013) Comparison of skin factors for perforated completions calculated with computationalfluid-dynamics software and the karakas-tariq semianalytical model. SPE Drill Complet 28(01):21-33. https://doi.org/10.2118/143663-pa
Wood BD, He X, Apte SV (2020) Modeling turbulent flows in porous media. Annu Rev Fluid Mech 52(01):171-203

Yildiz T (2006) Assessment of total skin factor in perforated wells. SPE Reservoir Eval Eng 9(01):61-76

Yuan B, Wood DA (2018) A comprehensive review of formation damage during enhanced oil recovery. J Petrol Sci Eng 167:287-299

Zheng L, Rahman MA, Ahammad MJ, Butt SD, Alam JM (2016) Experimental and numerical investigation of a novel technique for perforation in petroleum reservoir. the SPE International Conference and Exhibition on Formation Damage Control. Lafayette, Louisiana, USA.

Publisher's Note Springer Nature remains neutral with regard to jurisdictional claims in published maps and institutional affiliations. 